\title{
Variation of $\beta$-carotene Concentration in Soybean Seed and Sprout
}

\author{
Eun-Young Kang, Eun-Hye Kim, III-Min Chung, and Joung-Kuk Ahn \\ Department of Applied Bio Science, College of Life and Environmental Science, Konkuk University, Seoul 143-701, Korea
}

\begin{abstract}
In this study, $\beta$-carotene concentrations was determined in soybean cultivar according to seed size, usage, seed coat color and cotyledon color as well as the process of seed germination. The total average concentration of $\beta$ -carotene was $6.6 \mu \mathrm{g} / \mathrm{g}$ in soybean seed, $33.3 \mu \mathrm{g} / \mathrm{g}$ in soybean sprout. According to seed size, the total $\beta$-carotene concentration of soybean was $6.9 \mu \mathrm{g} / \mathrm{g}$ in large soybean seed, 6.7 $\mu \mathrm{g} / \mathrm{g}$ in medium soybean seed, and $6.31 \mu \mathrm{g} / \mathrm{g}$ in small soybean seed. In soybean sprout, the total $\beta$-carotene concentration was $21.4 \mu \mathrm{g} / \mathrm{g}$ in large soybean sprout, $30.5 \mu \mathrm{g} / \mathrm{g}$ in medium soybean sprout, and $43.5 \mu \mathrm{g} / \mathrm{g}$ in small soybean sprout. According to the utilization of seed, the total $\beta$-carotene concentration of soybean seed was $7.2 \mu \mathrm{g} / \mathrm{g}$ in cooked with rice soybean seed, $6.1 \mu \mathrm{g} / \mathrm{g}$ in paste and curd soybean seed, and $6.3 \mu \mathrm{g} / \mathrm{g}$ in sprout soybean seed. In soybean sprout, the total $\beta$-carotene concentration was $25.9 \mu \mathrm{g} / \mathrm{g}$ in cooked with rice soybean sprout, $32.4 \mu \mathrm{g} / \mathrm{g}$ in paste and curd soybean sprout, and $41.9 \mu \mathrm{g} / \mathrm{g}$ in sprout soybean sprout. When comparison with seed coat color, the total $\beta$-carotene concentration of soybean with brown seed coat $(8.8 \mu \mathrm{g} / \mathrm{g})$ was slightly higher than those of soybean with yellow $(6.1 \mu \mathrm{g} / \mathrm{g})$. In soybean sprout, the total $\beta$-carotene concentration was $21.8 \mu \mathrm{g} / \mathrm{g}$ in black seed coat sprout, $38.7 \mu \mathrm{g} / \mathrm{g}$ in brown seed coat sprout, $34.1 \mu \mathrm{g} / \mathrm{g}$ in green seed coat sprout, $39.5 \mu \mathrm{g} / \mathrm{g}$ in yellow seed coat sprout, and $30.5 \mu \mathrm{g} / \mathrm{g}$ in mottle seed coat sprout. The results of this study suggested the functional characteristics of soybean through quantitative analysis of $\beta$-carotene.
\end{abstract}

Keywords : $\beta$-carotene, soybean, seed, sprout

Approximately 100 million tons per year or more carotenoids are produced in the natural ecosystem (Kim et al., 1997). And, the carotenoids content in plant affected by genetics and their external environment (Bauernfeind, 1973). The carotenoids belong to tetra-terpenoid $\left(\mathrm{C}_{40}\right)$ group and shows orange color, usually fat-soluble (Kim, 2001; Simpson and Chichester, 1981). In addition, that is very unstable substance, so oxidation or isomerization takes place easily (Kim, 2001).

Nutritional importance of carotenoids are the provitamin A activity, food colorants, antioxidant activity, anticarcinogenic substance, oxygen transporters, immune activation, absorbers of light energy. Of these, $\beta$-carotene has $\beta$-rings at both ends, the most powerful active oxygen remover and the highest vitamin A activity (Kim, 2001 ; Jo and Jung, 2000 ; Stahelin et al., 1991 ; Lee and Kim, 1997 ; Kim et al., 1997). Also, it reduces the risk of prostatic cancer, related to the arteriosclerosis and cardiovascular disease, and inhibition of LDL oxidation (Kirsh et al., 2006 ; Oliver et al., 1998 ; Mascio et al., 1991). And, it has been known low carotene was related to a bronchus cancer (Stahelin et al., 1991).

Because the human body cannot synthesize vitamin A itself, human must be obtained from the diet. In other words, no side effects as $\beta$-carotene intake is recommended, this is converted into vitamin $\mathrm{A}$ in the body (Provitamin A).

Soybean sprout is short growing time and short relatively easy to grow, low price, and also occupies a large proportion in the daily diet (Oh et al., 2007). Mainly, the soybean sprouts grown to 100 -seed weight range was $7-15 \mathrm{~g}$, and smaller seed has the higher the yield of soybean sprouts, good vitality, excellent hypocotyls growth (Lee et al., 2002 ; Bates and Matthews, 1975). Seed nutrition was changed in germination process, while the fat content was reduced, fiber and crude protein were increased and especially, remarkable increase in the content of vitamins (Kim, 1981). In particular, vitamin $\mathrm{C}$ is not found in soybean seed, but it is synthesized in the germination process (Kim et al., 1993 ; Kim et al., 2007). Shimoyamada et al. (1991) reported that

\footnotetext{
${ }^{\dagger}$ Corresponding author: (Phone) +82-2-450-3730 (E-mail) jkahn@konkuk.ac.kr

$<$ Received 16 July , 2012; Revised 18 September, 2012; Accepted 25 September, 2012>
} 
after germination, fresh weight was increased an 8-fold, and dry weight was not changed. Kim et al. (2003) reported that isoflavone content was increased about 1 times in the process of germination. Among the soybean sprouts, green sprout had a high nutritional value, specially.

In our study, $\beta$-carotene contents of soybeans examined according to the size, usage, seed coat color and cotyledon color as well as the process of seed germination.

\section{MATERIALS \& METHODS}

\section{Preparation of samples}

The 68 Korean soybean varieties were cultivated at Yesan of Chungnam in 2006, according to standard cultivation method. Soybean seed were harvested at triplicate replications in each cultivar and stored at $4^{\circ} \mathrm{C}$ for analysis of $\beta$-carotene. The varieties were classified according to the seed coat color, cotyledon color, 100-seed weight and usage.

In this study, soybean was classified into three types, large (above $25 \mathrm{~g}, 22$ varieties), medium (15-25 g, 27 varieties), and small (below $15 \mathrm{~g}, 30$ varieties) by 100 -seed weight, respectively. Soybean sprout was prepared with following procedure. $4 \mathrm{~g}$ of soybean seed was washed and submerged in tap water at $20 \pm 2^{\circ} \mathrm{C}$ for $12 \mathrm{~h}$. Seed was spread uniformly in conical tube with holes and gave enough water more than 6 times a day, and cultivated five days in the dark chamber. After all soybean and soybean sprout was freezedried at $47^{\circ} \mathrm{C}$, and then, crushed and stored in dessicator for analysis. When the soybean sprout was grown by absorbing water, its weight was increased the four times, compared to the seed fresh-weight. But, freeze-dried to completely remove the water, weight was reduced $22 \%$, compared to the seed fresh-weight. Similarly, Shimoyamada et al. (1991) reported that during seed germination, seed fresh weight was increased about 8 times, while seed dry weight did not changed.

\section{Analysis of $\beta$-carotene}

The concentration of $\beta$-carotene was analyzed by the modified method of Jo and Jung (2000). The $1 \mathrm{~g}$ of finely ground soybean seed and sprout powder were extracted with $40 \mathrm{~mL}$ of acetone : petroleum ether $=1: 1$ solution and stirred $30 \mathrm{~min}$ at room temperature. The suspension was filtered through Whatman filter paper (No. 4). This process repeated twice in each sample. The extract was transferred to a separatory-funnel and added $50 \mathrm{~mL}$ of saturated sodium chloride solution, then mixed. To obtain a supernatant, wait until the layer was separated, and then was added $100 \mathrm{~mL}$ of distilled water, then mixed. The following process was expressed as saponification. But Oliver et al. (1998) reported that the photo-diode array detection enables the spectra of each individual peak of the chromatogram, it could allow carotenoid separation without sample saponification. And Khachik et al. (1986) reported that saponification of carotenoid extracts underestimated the individual carotenoid content (Individual carotenoid contents were reduced by saponification). For this reasons, saponification was omitted in this experiment.

After obtaining a supernatant, residual moisture was removed by sodium sulfate anhydrous. Supernatant was transferred to a $100 \mathrm{~mL}$ round flask and evaporated to dryness under reduced pressure using a rotary vacuum evaporator at below $35^{\circ} \mathrm{C}$, and the remaining residue was reconstituted with 4 $\mathrm{mL}$ of $0.01 \%$ BHT (Butylated Hydroxy Toluene) in chloroform. The aliquot sample was filtered through a $0.2 \mu \mathrm{m}$ nylon filter (TITAN, USA) and analyzed by HPLC. For all of the experimental process was conducted in dark condition. All of solvents were used as HPLC grade (J. T. Baker, USA) without further purification and all of reagents were used as special grade (Junsei, Japan).

The HPLC system was consists of SPD-M10A Photo Diode Array (PDA) Detector (Shimazu, Japan), Midas auto-injector (Younglin, Korea) and a $20 \mu \mathrm{L}$ sample loop and LC-10AD VP pump. The separation of $\beta$-carotene was performed by ODS $\mathrm{C}_{18}$ column $(250 \times 4.6 \mathrm{~mm}$ I.D. $)$. The maximum absorption wavelength of $\beta$-carotene was measured at 452 $\mathrm{nm}$. The mobile phase was followed, methanol $(\mathrm{MeOH})$ : tetrahydrofuran $(\mathrm{THF})=8: 2$, isocratic. In selecting the appropriate solvent ratio for analysis, several solvents combinations were done. Because a $\beta$-carotene is a non-polar substance, the percentage of THF (non-polar solvents) increased in mobile phase. Retention time (RT) was detected at 13.7 min. Running time was $25 \mathrm{~min}$ and flow rate was $1 \mathrm{~mL} / \mathrm{min}$. The $\beta$-carotene standard, which was purchased from Sigma -Aldrich (USA), was used to make the calibration curve. The $\beta$-carotene standard was dissolved in $0.01 \%$ BHT in 
$4 \mathrm{~mL}$ chloroform, the plotting standards were made at four concentrations of $25,50,100$ and $250 \mu \mathrm{g}$, and a high linearity $\left(\mathrm{R}^{2}=0.996\right)$ was obtained. The interpretation of the $\beta$-carotene was supported its retention time ( $\beta$-carotene : $13.7 \mathrm{~min}$ ) and adsorption spectra in HPLC.

\section{Statistical analysis}

The analysis of statistical was undertaken using the general linear model procedure (GLM) of the statistical analysis program (SAS, 2000). All experiments were determined as duplicates. The least significant difference (LSD) test was based on the 0.05 probability level.

\section{RESULTS AND DISCUSSION}

The total average concentration of $\beta$-carotene was 6.6 $\mu \mathrm{g} / \mathrm{g}$ in soybean seed, $33.3 \mu \mathrm{g} / \mathrm{g}$ in soybean sprout. In comparison with soybean seed, soybean sprout increased about 5 times for total average of $\beta$-carotene concentration. And the average concentration of $\beta$-carotene in soybean seed and sprout was significantly different $(\mathrm{p}<0.05)$ (Fig. $1)$. That is, $\beta$-carotene content was increased significantly in the germination process. These results is similar to those of previous studies by Kim et al. (1993) and Liu (1997), who demonstrated that $\beta$-carotene content increased 17-fold during seed germination process on the dry weight. Also, $\beta$-carotene content in the soybean sprout was 6 times higher than that of soybean seed. In soybean seed, $\beta$-carotene concentration of Cheongbang-kong $(12.9 \mu \mathrm{g} / \mathrm{g})$ was the highest

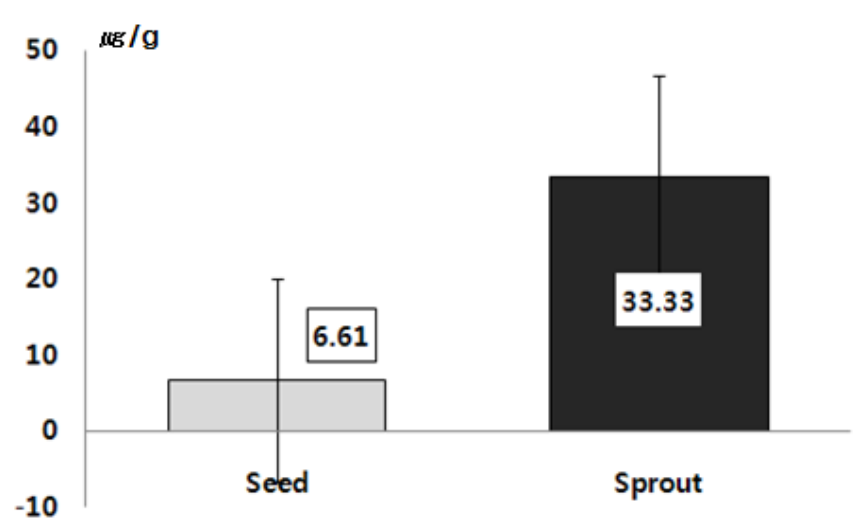

Fig. 1. Comparison of $\beta$-carotene concentration between soybean seed and sprout.

*Each vertical bar indicates the standard error values. content, while, Sojin-kong $(5.8 \mu \mathrm{g} / \mathrm{g})$ was the lowest content. In soybean sprout, total $\beta$-carotene concentration of Buakdarikong $(75.8 \mu \mathrm{g} / \mathrm{g})$ was the highest content, while, Ogapi-kong $(6.5 \mu \mathrm{g} / \mathrm{g})$ was the lowest content.

The result of this study may provide plant breeders with information for selecting soybean varieties that contain high concentrations of $\beta$-carote ne. Also, this results will be helpful as basic information for food industries.

\section{Concentration of $\beta$-carotene, according to the seed size}

In this study, oybean varieties were classified as large (above $25 \mathrm{~g}, 16$ varieties), medium (15 $\sim 25 \mathrm{~g}, 26$ varieties), and small (below $15 \mathrm{~g}, 26$ varieties) based on 100-seed weight. The total $\beta$-carotene concentration of soybean seed was ranged from 5.9 to $11.8 \mu \mathrm{g} / \mathrm{g}$ in large soybean seed, from 5.8 to $12.9 \mu \mathrm{g} / \mathrm{g}$ in medium soybean seed, and from 5.8 to $7.6 \mu \mathrm{g} / \mathrm{g}$ in small soybean seed. In soybean sprout, the total $\beta$-carotene concentration was ranged from 6.5 to $41.9 \mu \mathrm{g} / \mathrm{g}$ in large soybean sprout, from 7.7 to $75.8 \mu \mathrm{g} / \mathrm{g}$ in medium soybean sprout, and from 11.4 to $73.6 \mu \mathrm{g} / \mathrm{g}$ in small soybean sprout (Table 1). According to the seed size,

Table 1. Comparison of $\beta$-carotene concentration between soybean seed and sprout on seed size difference.

\begin{tabular}{|c|c|c|c|}
\hline \multirow{2}{*}{\multicolumn{2}{|c|}{ Seed size }} & Seed & Sprout \\
\hline & & ---------. & ---------- \\
\hline \multirow{5}{*}{$\begin{array}{l}\text { Large seed } \\
\text { (16 varieties) }\end{array}$} & Maximum & 11.8 & 41.92 \\
\hline & Minimum & 5.9 & 6.45 \\
\hline & Mean & 6.88 & 21.44 \\
\hline & CV (\%) & 8.99 & 9.95 \\
\hline & LSD (0.05) & 1.31 & 4.52 \\
\hline \multirow{5}{*}{$\begin{array}{l}\text { Medium seed } \\
\text { (26 varieties) }\end{array}$} & Maximum & 12.85 & 75.77 \\
\hline & Minimum & 5.82 & 7.68 \\
\hline & Mean & 6.74 & 30.52 \\
\hline & CV (\%) & 8.92 & 15.77 \\
\hline & LSD $(0.05)$ & 1.24 & 9.90 \\
\hline \multirow{5}{*}{$\begin{array}{l}\text { Small seed } \\
(26 \text { varieties })\end{array}$} & Maximum & 7.61 & 73.55 \\
\hline & Minimum & 5.78 & 11.35 \\
\hline & Mean & 6.31 & 43.46 \\
\hline & CV (\%) & 5.07 & 10.44 \\
\hline & LSD (0.05) & 0.66 & 9.32 \\
\hline
\end{tabular}


the total $\beta$-carotene in soybean seed was not significant different $(\mathrm{p}<0.05)$. Whereas, the soybean sprout concentration according to different seed size was significant difference $(\mathrm{p}<0.05)$.

In the $\beta$-carotene concentration change during germination process, large soybean seed was $14.6 \mu \mathrm{g} / \mathrm{g}$ (312\%), medium soybean seed was $23.8 \mu \mathrm{g} / \mathrm{g}$ (453\%), and small soybean seed showed $37.2 \mu \mathrm{g} / \mathrm{g}(689 \%)$. The total $\beta$-carotene was significantly increased in small soybean seed. From this study, $\beta$-carotene concentrations of soybean sprouts higher than soybean seeds and showed difference by seed size.

\section{Concentration of $\beta$-carotene, according to the seed usage}

According to seed usage, soybeans divided into three types : cooked with rice (27 varieties), paste and curd (16 varieties), and sprout ( 25 varieties). The total $\beta$-carotene concentration of soybean seed was ranged from 5.8 to 12.9 $\mu \mathrm{g} / \mathrm{g}$ in cooked with rice soybean seed, from 5.8 to $6.5 \mu \mathrm{g} / \mathrm{g}$ in paste and curd soybean seed, and from 5.8 to $7.6 \mu \mathrm{g} / \mathrm{g}$ in sprout soybean seed. In soybean sprout, the total $\beta$ -carotene concentration was ranged from 6.5 to $71.1 \mu \mathrm{g} / \mathrm{g}$

Table 2. Comparison of $\beta$-carotene concentration between soybean seed and sprout on seed usage.

\begin{tabular}{clrr}
\hline \hline \multirow{2}{*}{ Seed usage } & \multicolumn{2}{c}{ Seed } & Sprout \\
\cline { 3 - 4 } & & $-------\mu \mathrm{g} / \mathrm{g}$ & --------- \\
\hline & Maximum & 12.85 & 71.13 \\
Cooked with rice & Minimum & 5.81 & 6.45 \\
(27 varieties) & Mean & 7.21 & 25.91 \\
& CV (\%) & 9.90 & 10.87 \\
& LSD (0.05) & 1.46 & 5.78 \\
\hline & Maximum & 6.47 & 70.43 \\
Paste and curd & Minimum & 5.82 & 7.68 \\
(16 varieties) & Mean & 6.06 & 32.42 \\
& CV (\%) & 5.49 & 18.68 \\
& LSD (0.05) & 0.71 & 12.84 \\
\hline & Maximum & 7.61 & 75.77 \\
& Minimum & 5.78 & 11.35 \\
Sprout & Mean & 6.31 & 41.94 \\
& CV (\%) & 5.16 & 9.65 \\
& LSD (0.05) & 0.67 & 8.34 \\
\hline
\end{tabular}

in cooked with rice soybean sprout, from 7.7 to $70.4 \mu \mathrm{g} / \mathrm{g}$ in paste and curd soybean sprout, and from 11.4 to 75.8 $\mu \mathrm{g} / \mathrm{g}$ in sprout soybean sprout (Table 2). The total $\beta$ -carotene in soybean seed and sprout as based on their seed usage was significantly different $(p<0.05)$ (Fig. 3).

$\beta$-carotene concentration increased during germination process. Cooked with rice soybean seed was $18.7 \mu \mathrm{g} / \mathrm{g}$ (359\%), paste and curd soybean seed was $26.4 \mu \mathrm{g} / \mathrm{g}$ (535\%), sprout soybean seed was $35.6 \mu \mathrm{g} / \mathrm{g}(664 \%)$. The total $\beta$-carotene significantly increased in sprout soybean seed.

As a result, the concentration of total $\beta$-carotene was increased with germination process, and depends on the

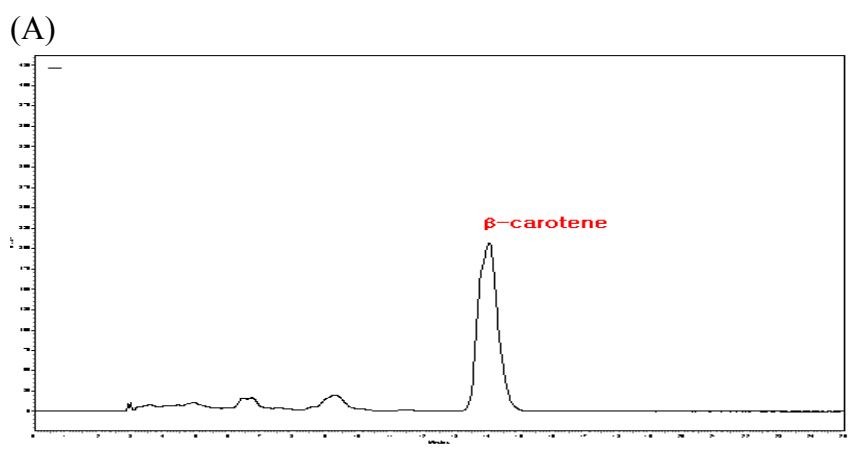

(B)

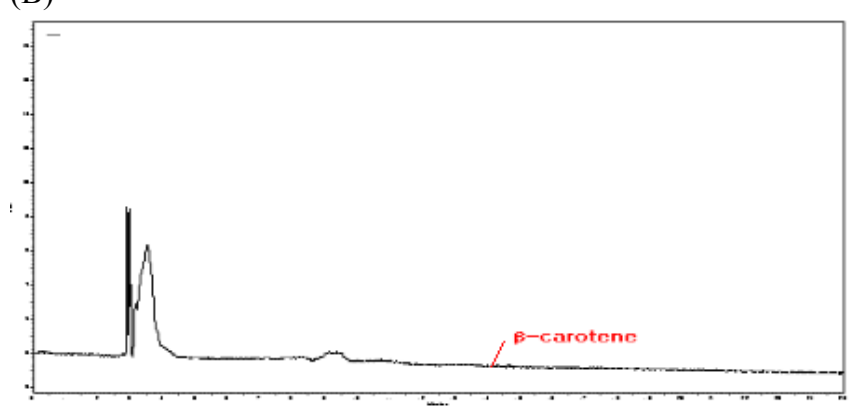

(C)

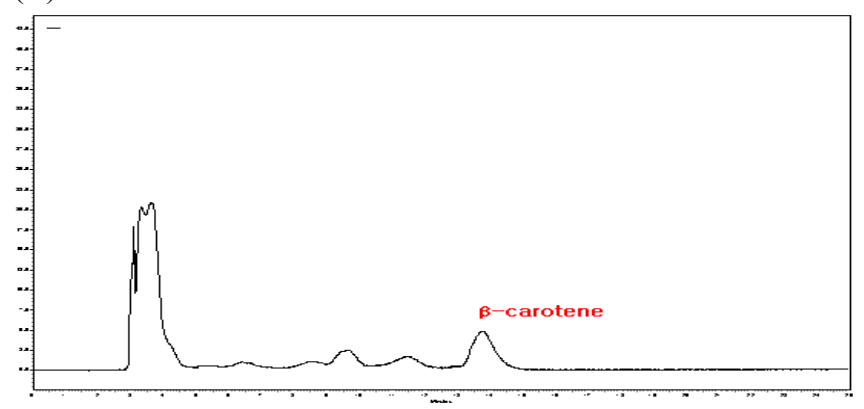

Fig. 2. The chromatogram of $\beta$-carotene in Akjongdari-kong soybean seed and sprout.

(A) $\beta$-carotene standard; (B) Akjongdarikong soybean; (C) Akjongdari-kong soybean sprout. 

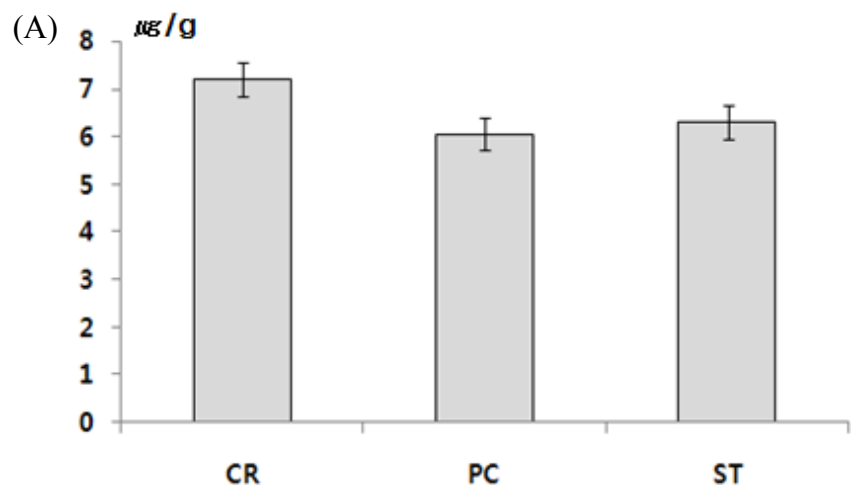

(B)

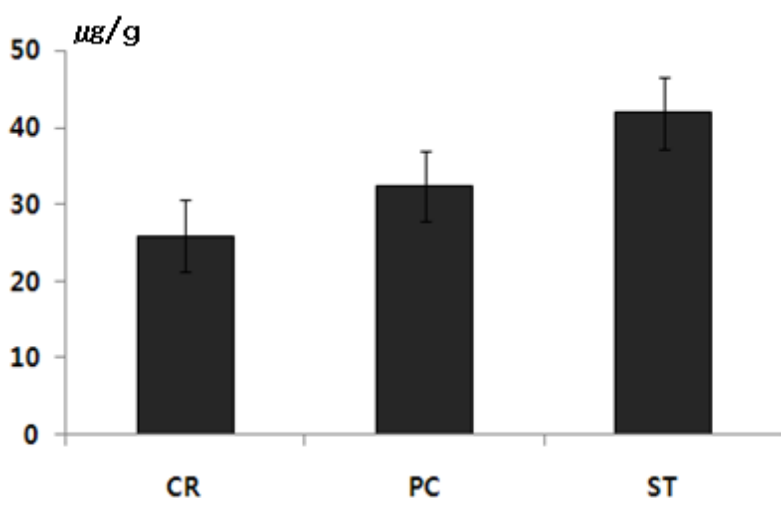

Fig. 3. Comparison of $\beta$-carotene concentration in soybean seed and sprout on seed usage.

*Each vertical bar indicates the standard error values. A, soybean seed; B, soybean sprout; CR, cooked with rice ; $\mathrm{PC}$, paste and curd ; $\mathrm{ST}$, sprout.

usage of soybean seed. The large and medium soybean has been mainly used as a cooked with rice soybean, and paste and curd soybean, small soybean seed has been used as sprout seed. In this point, it could be connected with the result of on the seed size.

\section{Concentration of $\beta$-carotene, according to the seed coat color}

Soybean seeds were divided into five types according to seed coat colors : black (17 varieties), brown (3 varieties), green (13 varieties), yellow (30 varieties), and mottle (5 varieties). The total $\beta$-carotene concentration of soybean with brown seed coat $(8.8 \mu \mathrm{g} / \mathrm{g})$ was slightly higher than those of soybean with yellow $(6.1 \mu \mathrm{g} / \mathrm{g})$ (Fig. 4). In soybean sprout, the total $\beta$-carotene concentration was $21.8 \mu \mathrm{g} / \mathrm{g}$ in black seed coat sprout, $38.7 \mu \mathrm{g} / \mathrm{g}$ in brown seed coat sprout, $34.1 \mu \mathrm{g} / \mathrm{g}$ in green seed coat sprout, $39.5 \mu \mathrm{g} / \mathrm{g}$ in yellow

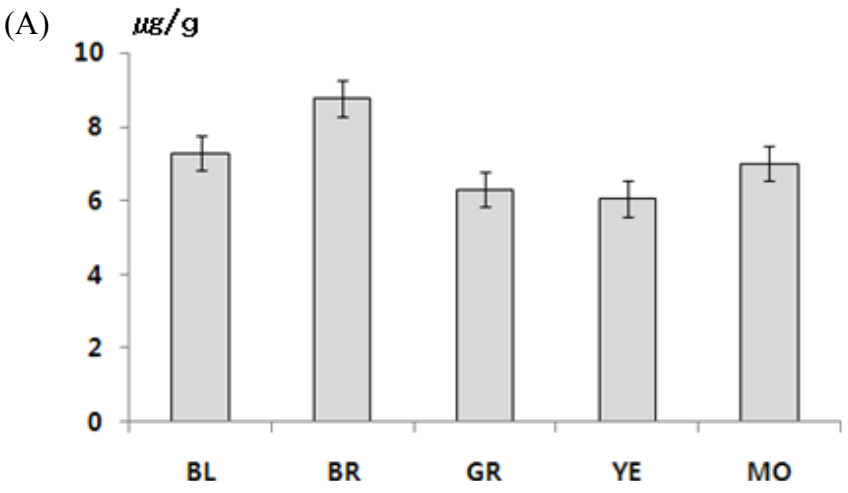

(B)

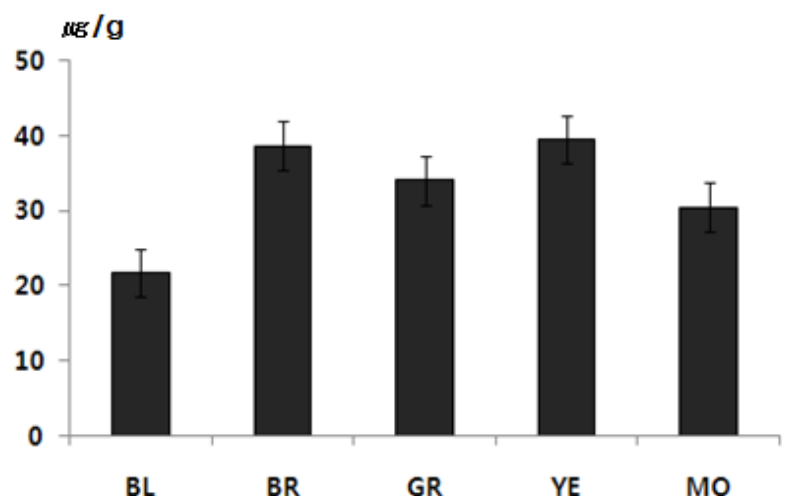

Fig. 4. Comparison of $\beta$-carotene concentration in soybean seed and sprout on seed coat color.

*Each vertical bar indicates the standard error values. (A) soybean seed; (B) soybean sprout; BL, black; $\mathrm{BR}$, brown ; GR, green; YE, yellow; MO, mottle.

seed coat sprout, and $30.5 \mu \mathrm{g} / \mathrm{g}$ in mottle seed coat sprout.

In germination process, $\beta$-carotene concentration change of yellow seed coat soybean seed was $33.5 \mu \mathrm{g} / \mathrm{g}(652 \%)$, brown was $29.9 \mu \mathrm{g} / \mathrm{g}$ (440\%), green was $27.8 \mu \mathrm{g} / \mathrm{g}(539 \%)$, mottle was $23.5 \mu \mathrm{g} / \mathrm{g}(434 \%)$, and black was $14.5 \mu \mathrm{g} / \mathrm{g}$ (298\%). The total $\beta$-carotene content significantly increased in yellow seed coat soybean.

Consequently, the total $\beta$-carotene accumulation of soybeans showed differnce according to their seed oat color.

\section{Concentration of $\beta$-carotene, according to the seed cotyledon color}

The soybean samples divided into two types according to cotyledon color, that green (14 varieties) and yellow (54 varieties). The total $\beta$-carotene concentration of soybean with green cotyledon $(7.7 \mu \mathrm{g} / \mathrm{g})$ was higher than those of soybean with yellow $(6.3 \mu \mathrm{g} / \mathrm{g})$, and content difference was 
significant $(\mathrm{p}<0.05)$. In soybean sprout, the total $\beta$-carotene concentration was $24.5 \mu \mathrm{g} / \mathrm{g}$ in green cotyledon sprout, and

Table 3. Comparison of $\beta$-carotene concentration between soybean seed and sprout on seed cotyledon color.

\begin{tabular}{|c|c|c|c|}
\hline \multirow{2}{*}{\multicolumn{2}{|c|}{ Seed cotyledon color }} & Seed & Sprout \\
\hline & & \multicolumn{2}{|c|}{-------- $\mu \mathrm{g} / \mathrm{g}$--------- } \\
\hline \multirow{5}{*}{$\begin{array}{c}\text { Green } \\
\text { (14 varieties) }\end{array}$} & Maximum & 12.85 & 71.13 \\
\hline & Minimum & 5.80 & 6.86 \\
\hline & Mean & 7.68 & 24.55 \\
\hline & CV (\%) & 12.45 & 9.30 \\
\hline & LSD $(0.05)$ & 2.05 & 4.90 \\
\hline \multirow{5}{*}{$\begin{array}{c}\text { Yellow } \\
\text { (54 varieties) }\end{array}$} & Maximum & 8.29 & 75.77 \\
\hline & Minimum & 5.78 & 6.45 \\
\hline & Mean & 6.33 & 35.61 \\
\hline & CV (\%) & 4.98 & 12.89 \\
\hline & LSD $(0.05)$ & 0.63 & 9.20 \\
\hline
\end{tabular}

(A)

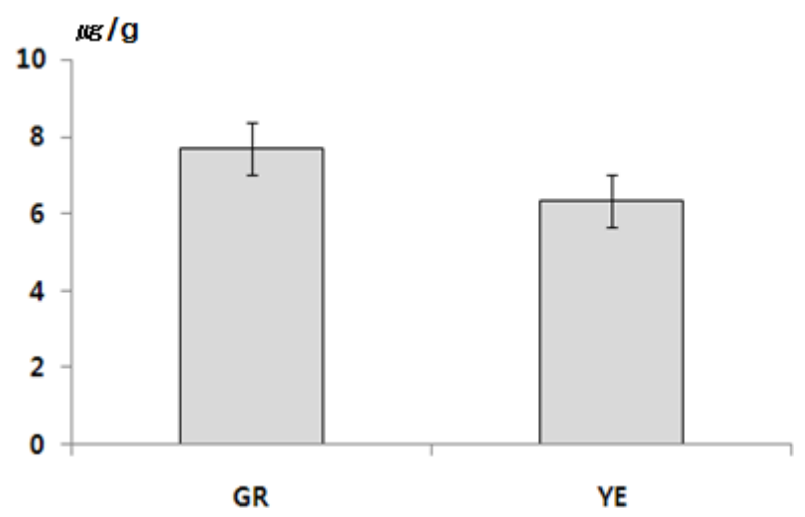

(B)

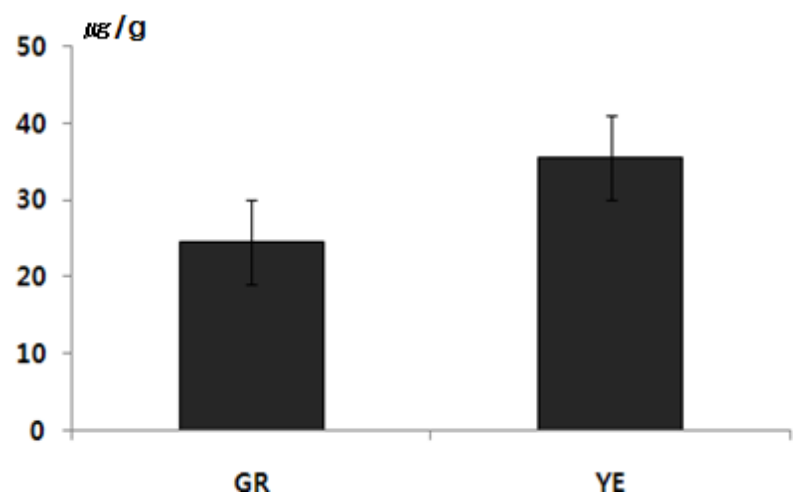

Fig. 5. Comparison of $\beta$-carotene concentration in soybean seed and sprout on seed cotyledon color.

*Each vertical bar indicates the standard error values. (A) soybean seed; (B) soybean sprout; GR, green ; YE, yellow.
$35.6 \mu \mathrm{g} / \mathrm{g}$ in yellow cotyledon sprout, however, content difference was not significant $(\mathrm{p}<0.05)$ (Table 3, Fig. 5). During germination, the content of total $\beta$-carotene increased in green $(16.9 \mu \mathrm{g} / \mathrm{g}, 319 \%)$, yellow $(29.3 \mu \mathrm{g} / \mathrm{g}, 562 \%)$. The total $\beta$-carotene was significantly increased in yellow seed coat soybean.

From this study, the average total $\beta$-carotene concentrations affected by seed cotyledone color. And $\beta$-carotene concentrations increased during germination process.

\section{ACKNOWLEDGEMENT}

This paper was written as part of Konkuk University's research support program for its faculty on sabbatical leave in 2011 .

\section{REFERENCES}

Bates, R. P. and R. F. Matthews. 1975. Ascorbic acid and $\beta$ -carotene in soybeans as influenced by maturity, sprouting, processing, and storage. Florida State Horticultural Society. 266-271.

Bauernfeind, J. C. 1973. Carotenoid vitamin A precursors and analogs in foods and feeds. J. Agric. Food Chem. 20(3) : 456-473.

Jo, J. O. and I. C. Jung. 2000. Changes in carotenoid contents of several green-yellow vegetables by blanching. Kor. J. Food Cookery Sci. 16(1) : 17-21.

Khachik, F., G. R. Beecher, and N. F. Whittaker. 1986. Separation, identification, and quantification of the major carotenoid and chlorophyll constituents in extracts of several green vegetables by liquid chromatography. J. Agric. Food Chem. 34(4) : 603-616.

Kim, J. W. 2001. Methodology of Carotenoids Chemistry. Kor. J. Food Nutr. 14(4) : 360-366.

Kim, K. H. 1981. Studies on the growing characteristics of soybean sprout. Kor. J. Food Sci. Technol. 13(3) : 247-252.

Kim, M. J., J. H. Kim, H. K. Oh, M. J. Chang, and S. H. Kim. 2007. Seasonal variations of nutrients in Korean fruits and vegetables : Examining water, protein, lipid, ascorbic acid, and $\beta$-carotene contents. Kor. J. Food Cookery Sci. 23(4) : 423-432.

Kim, S. D., S. H. Kim, and E. H. Hong. 1993. Composition of soybean sprout and its nutritional value. Kor. Soybean Dig. 10(1) : 1-9.

Kim, S. J., J. W. Rhim, S. T. Jung, Y. S. Ahn, and Y. B. Oh. 1997. Carotenoid contents of yellow sweet potatoes. Kor. J. Food Sci. Technol. 29(2) : 218-222. 
Kim, Y. H., Y. H. Hwang, and H. S. Lee. 2003. Analysis of isoflavones for 66 varieties of sprout beans and bean sprouts. Kor. J. Food Sci. Technol. 35(4) : 568-575.

Kirsh, V. A., R. B. Hayes, S. T. Mayne, N. Chatterjee, A. F. Subar, L. B. Dixon, D. Albanes, G. L. Andriole, D. A. Urban, and U. Peters. 2006. Supplemental and dietary vitamin $\mathrm{e}, \beta$-carotene, and vitamin $\mathrm{c}$ intakes and prostate cancer risk. Journal of the National Cancer Institute 98(4) : 245-254.

Lee, H. S. and Y. N. Kim. 1997. Beta-carotene and lutein contents in green leafy vegetables. Journal of the East Asian of Dietary Life. 7(2) : 175-180.

Lee, J. D., Y. H. Hwang, H. Y. Cho, D. U. Kim, and M. G. Choung. 2002. Comparison of characteristics related with soybean sprouts between Glycine max and G. soja. Kor. J. Crop Sci. 47(3) : 189-195.

Liu, K. S. 1997. Soybeans: chemistry, technology, and utilization. An aspen publication. 203-205.

Mascio, P. D., M. E. Murphy, and H. Sies, H. 1991. Antioxidant defense systems: the role of carotenoids, tocopherols, and thiols. Am. J. Clin. Nutr. 53 : 194S-200S.

Oh, B. Y., B. H. Park, and K. S. Ham. 2007. Effects of chitosan treatment on changes of soyasaponin contents in soybean sprouts. J. Kor. Soc. Food Sci. Nutr. 36(5) : 584-588.

Oliver, J., A. Palou, and A. Pons. 1998. Semi-quantification of carotenoids by high-performance liquid chromatography: saponification-induced losses in fatty foods. J. Chromatography A. 829(1-2) : 393-399.

Shimoyamada, M., K. Harada, and K. Okubo. 1991. Saponin composition in developing soybean seed (Glycine max (L.) MERRILL, cv. Mikuriyaao). Agric. Biol. Chem. 55(5) : 1403-1405.

Simpson, K. L. and C. O. Chichester. 1981. Annual Review of Nutrition. Metabolism and nutritional significance of carotenoids. Vol. 1 : 351-374.

Stahelin, H. B., K. F. Gey, M. Eichholzer, and E. Ludin. 1991. $\beta$-carotene and cancer prevention: the Basel Study. Am. J. Clin. Nutr. $53: 265 \mathrm{~S}-269 \mathrm{~S}$. 